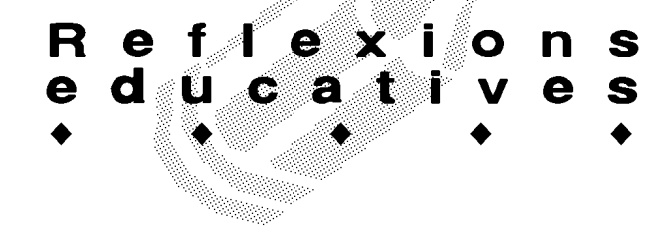

\title{
METODOLOGIA COMPARADA EN L'EDUCACIÓ MUSICAL: KODÀLY, ORFF I DALCROZE. IMPLICACIONS PER A LA CONSTRUCCIÓ D'UNA DIDÀCTICA DE LA MÚSICA
}

\author{
Enriqueta Barniol Terricabres. Àrea de Didàctica de la Música. URV.
}

\section{Introducció}

Aquest treball que aquí es presenta és un estudi emmarcat dins la tesi doctoral de l'autora de l'article.

Kodàly (1882-1967) va néixer a Kecskemet (Hongria). Fou compositor, musicòleg i folklorista, i exercí de professor a l'Acadèmia Nacional de Música de Budapest. Va recórrer tot el país recollint melodies populars. Les seves obres tenen un marcat caràcter nacional hongarès. Karl Orff (1895-1982), nascut a Munich, fou compositor i professor de la Hochschule für Musik. Jacques Dalcroze (18651950), és d'origen suís, tot i haver nascut a Viena. Fou compositor i professor del Conservatori de Ginebra. Davant la realitat que se li presentava al tractar de formar musicalment la joventut, creà un sistema d'educació a partir del ritme conegut per tothom com la Rítmica Dalcroze.

\section{Els mètodes d'educació musical}

Quan un evoca els noms de Kodàly, Dalcroze, Orff els associa a "mètodes" d'educació musical. Per la seva popularitat i presència constant en l'educació musical, prenem els models de Kodàly, Dalcroze i Orff, tres eminents pedagogs musicals que han revolucionat l'ensenyament de la música en tots els seus aspectes en el segle XX.

Què volem expressar quan parlem de "mètodes"? Quines categories organitzen la descripció d'aquests principis didàctics? Existeixen coincidències i/o semblances entre els models analitzats?

La proliferació i la difusió de "mètodes" d'educació musical que s'ha succeït a Catalunya i a l'Estat espanyol, amb una absoluta manca d'unitat de plantejaments i en oberta oposició uns amb altres, ens ha portat a considerar alguns dels problemes que veiem en la formació inicial $\mathrm{i}$ permanent/continuada dels professors de música i a l'ensenyament de la música en els nivells no universitaris: 1) El coneixement dels fonaments i dels principis educatius que guien i orienten l'activitat de l'ensenyament musical. 2) I la qüestió permanent que es planteja el professorat: quin/s "mètode o mètodes" cal aplicar en l'ensenyament de la música?

Els professors tenen sovint una apreciació superficial d'aquests models; molt sovint creuen que es limiten a algunes tècniques $\mathrm{o}$ a algunes activitats pràctiques; $\mathrm{i}$ això provoca que es constitueixin partidaris dels diferents "mètodes". Sovint els especialistes d'un model concret jutgen negativament situacions dels altres sense conèixer-ne veritablement els trets característics. Ens sembla essencial, doncs, que els professors de música estiguin ben informats de la fonamentació i de les bases dels diferents models. És important que comprenguin el sentit dels seus objectius i la significació dels recursos didàctics essencials de cadascun d'ells. Cal doncs: 1) Explorar els fonaments on es basen cadascun d'aquest tres models. 2) Elaborar un sistema categòric d'aquests "mètodes". 3) Detectar en quina mesura s'assemblen o discrepen entre ells. 4) Establir la reflexió sobre la pràctica.

La premissa/hipòtesi que orienta i dóna sentit a aquest estudi es va perfilant en el procés del desenvolupament del treball $\mathrm{i}$ queda formulada de la següent manera:

- Aquests models estan articulats segons una varietat de filosofies i estils d'ensenyar música i comprenen enfocaments amb continguts i materials altament estructurats que insisteixen en la lliure exploració i experimentació.

- Han disposat, ordenat i enfocat el seu model, condicionant-lo a l'alumnat amb el qual treballen.

- Proposen un nou concepte d'educació musical i un conjunt d'idees i de principis que orienten la pràctica musical.

- L'ús d'un model concret és la millor fórmula, ja que seleccionar els millors aspectes de cada model i englobar-los per crear-ne un de propi només aconsegueix anul-lar els brillants resultats de cadascun d'ells i es fa incompatible, ja que cadascun s'estructura de manera diferent. 


\section{$R$ e f

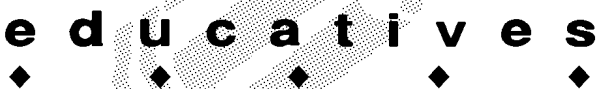

Per portar a terme aquest estudi hem contemplat els següents àmbits:

- Perspectiva històrica. On tractem breument l'evolució de les tendències educatives que s'han destacat en l'educació musical al llarg de la història.

- Marc pedagògic actual. Revisem el marc pedagògic musical actual.

- Utopies i fal/làcies. Utopies i fal-làcies respecte al tema (vegeu-ne alguns exemples en el quadre 1).

I el desenvolupem seguint aquest itinerari:

- Antecedents. Literatura especialitzada. Estada als països d'origen. Aplicació i adaptació dels mètodes en la docència de la música a l'ensenyament de règim general.

- Primera Fase. Selecció dels mètodes a comparar. Revisió de bibliografia escrita sobre els pedagogs i sobre estudis comparatius de pedagogia musical.

- Segona Fase. Anàlisi de la informació recollida.

- Tercera Fase. Anàlisi de la informació obtinguda: Reducció de dades. Estructuració de les dades. Extracció de resultats i conclusions (vegeu-ne alguns exemples en l'apartat 'L'aprenentatge rítmic, el melòdic, les habilitats auditives d'ordre melòdic, els elements expressius i mitjans d'expressió, el repertori, la lectura i escriptura i la improvisació, segons, Dalcroze, Orff i Kodàly").

- Quarta i última fase. Implicacions. Informe final.

L'aprenentatge rítmic, el melòdic, les habilitats auditives d'ordre melòdic, els elements expressius $\mathbf{i}$ mitjans d'expressió, el repertori, la lectura i escriptura i la improvisació, segons Dalcroze, Orff i Kodàly

Aprenentatge rítmic

Hi juga un rol molt particular. És el primer element introduït. És sensiblement el mateix. Revolucionant així el mètode tradicional, que comença amb la rodona, després amb la seva subdivisió en dues blanques i quatre negres... Comencen l'estudi del ritme a partir de:

- Dalcroze: Moviments naturals del nen.

- Orff: Llengua parlada i a partir del moviment. Dedica tot un primer any de formació musical a la rítmica $i$ fins al segon any (i a vegades fins $i$ tot més tard no s'introdueix el solfeig).

- Kodàly: Motius isolats emmarcats dins de les can-

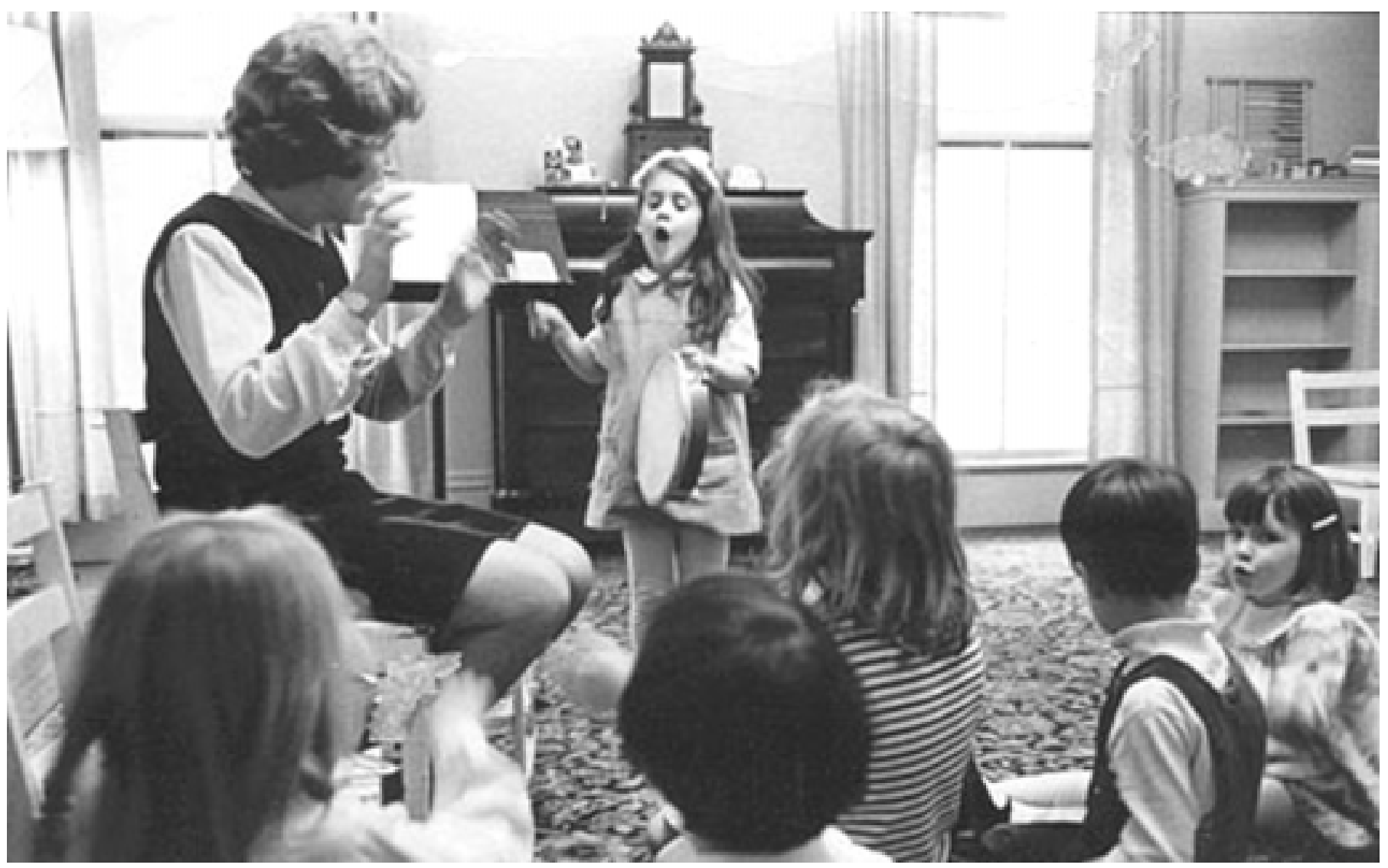

Classe de música al Dana School of Music, seguint el mètode Kodàly (any 1968) 


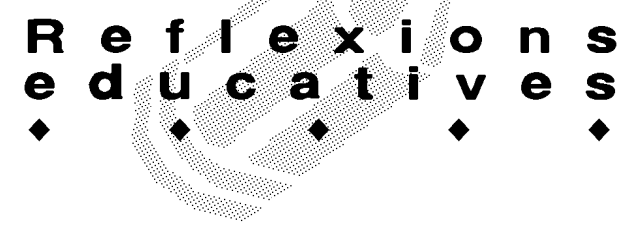

çons. S'introdueix al mateix temps que la primera relació melòdica.

\section{Aprenentatge melòdic}

Diferències importants caracteritzen cada enfocament. I els enfocaments Kodály i Orff fan servir tots dos una progressió de motius melòdics semblants, però persegueixen uns objectius ben diferents.

- Dalcroze: Estudi d'escales. Parteix del Do M. S'inicia amb el mig to, perquè dóna accés a l'estudi d'escales (encadenament de tons i mitjos tons).

- Orff: S'introdueix a partir de petits motius, cada un caracteritza una relació tonal concreta: 2 notes, 3,4 i finalment 5 per formar el mode pentatònic. Selecció de motius musicals com un mitjà per a cultivar la creativitat.

- Kodàly: S'introdueix a partir de petits motius, cada un caracteritza una relació tonal concreta: 2 notes, 3,4 i finalment 5 per formar el mode pentatònic. Selecció de motius musicals com a mitjà per desenvolupar les habilitats de lectura i escriptura.

\section{Habilitats auditives d'ordre melódic}

- Dalcroze: Do fix.

- Kodàly: Do mòbil. Introdueix el do fix després de tres anys de formació.

Elements expressius

- Dalcroze: És qui elabora més aquest aspecte considerant-lo tan important com el ritme i la melodia. Desenvolupa una gran sensibilitat cap als elements expressius. Fa servir un gran nombre d'activitats rítmiques que porten l'alumne a experimentar amb el seu cos els diferents matisos de "tempo", dinàmica i articulació de frases, etc.

- Orff: Precisa poc respecte a elements expressius. Només que han de ser considerats en les activitats d'iniciació musical i en les peces d'execució.

- Kodàly: Li assigna un paper important. Considera que per ser ben musical, tota interpretació vocal s'ha de preocupar per les frases, els matisos, els "tempo..."

Mitjans d'expressió

Tota vegada que cadascun privilegia un mitjà d'expressió particular, els altres mitjans d'expressió no són pas deixats de banda.

- Dalcroze: S'associa al moviment.

- Orff: S'associa a l'instrument.

- Kodàly: S'associa a la veu.

Repertori

- Dalcroze: Proposa un altre tipus de repertori. La música improvisada.

- Orff: Les cantarelles, les cançons infantils i les cançons populars tradicionals són el recurs principal. Ara bé, aquestes peces no són seleccionades amb la rigorositat de Kodàly.

- Kodàly: Es fonamenta en les cançons populars tradicionals. Posa una atenció especial en la selecció del seu repertori.

Lectura i escriptura

- Dalcroze: Ho considera essencial en tota la formació musical. I creu que cada element de notació

\section{Uns diuen que}

- Els defensors i seguidors dels mètodes es caracteritzen per un tarannà dogmàtic.

- Seguir un d'aquest mètodes limita la llibertat del professor en l'organització del contingut, de les activitats i de la forma com desitgen ensenyar la música.

- Algunes adaptacions d'aquests mètodes a altres països (un nou context musical educacional, cultural i social). Per exemple, l'ús de l'escala pentatònica defensada per Orff i Kodàly no és tan òbvia en el context català: la música popular catalana no té pràcticament sistema pentatònic.

- Els mètodes a vegades són simples receptes, i la seva aplicació fa perdre la creativitat del professor.

- El disseny curricular actual proposa un ventall d'objectius molt dispers que no es pot trobar en un de sol dels enfocaments (Dalcroze treballa el ritme des de l'àmbit de la rítmica corporal, cosa que Kodàly fa molt poc).

- Una realitat escolar, un espai insuficient, un material inexistent i una temporització molt curta de dedicació a la música no permeten l'aplicació fidel i rigorosa d'un únic enfocament.

- L'ús exclusiu de cançons pròpies d'aquests mètodes pot també constituir un problema que contribueix a perdre la identitat cultural del lloc on s'adapta el "mètode".

\section{I altres opinen que}

- El mètode no és un dogma, serveix per ajudar el professor en una línia de construcció.

- Tot al contrari, forneix d'una base de treball a partir de la qual el professor pot desenvolupar les seves pròpies idees i opinions.

- Un dels aspectes a tenir en consideració en el procés d'adopció d'una o més metodologies d'ensenyament és la capacitat del professor d'adaptarlo a la seva personalitat, a les seves creences i a les exigències de la realitat en què es mou.

- Cal fer servir elements de diferents enfocaments per construir-nos el nostre propi camí. 


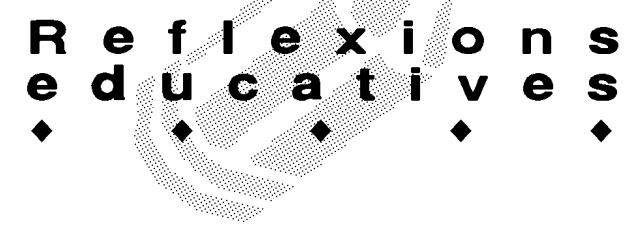

musical es fonamenta en una experiència concreta. Privilegia l'experiència sensible i auditiva en la lectura i escriptura musicals. La notació escrita no es presenta fins que els conceptes de base estiguin suficientment impregnats i interioritzats. La notació es presenta després de moltíssimes experiències diferents i no és desenvolupada de forma sistemàtica i urgent com Kodàly.

- Orff: Com que el seu objectiu és desenvolupar la creativitat, no dóna gaire importància a les habilitats de lectura i escriptura. Gran part d'aquest aprenentatge es fa a partir de: imitació i memorització. Notació musical: és una eina, però no una finalitat en si mateixa. Considera que per a la creació musical l'escriptura i la lectura no són indispensables.

- Kodàly: Ho considera essencial en tota la formació musical. I creu que cada element de notació musical es fonamenta en una experiència concreta. Són unes habilitats de primer rang en objectius perseguits. Té tota una progressió detallada i un conjunt de tècniques particulars per permetre als nens d'adquirir fàcilment aquestes habilitats. La notació musical segueix l'experiència tot seguit i pràcticament són desenvolupades paral·lelament. És desenvolupada de forma sistemàtica i urgent. Improvisació

- Dalcroze: Improvisació conscient d'elements coneguts. L'exploració lliure i les tècniques de música contemporània són treballades cada vegada més. La improvisació corporal es treballa i l'alumne ha d'experimentar per mitjà dels moviments lliures les diferents característiques musicals enteses. Els alumnes dalcrozians són molt hàbils en la improvisació al piano i en la improvisació musical.

- Orff: El seu objectiu és el desenvolupament de la creativitat, amb la qual cosa dóna curs lliure a la improvisació. Molta manipulació d'elements sonors i exploració de totes les combinacions sonores. Propugna la improvisació aleatòria i les descobertes imprevisibles. Improvisació vocal, corporal i instrumental.

- Kodàly: Una improvisació enquadrada dins d'un coneixement. La improvisació aleatòria és desaconsellada. Sempre fa servir de manera conscient els elements musicals que ja coneix. Només fa improvisació vocal.

\section{Conclusions}

Trets coincidents

- La creença en el valor intrínsec i educatiu de la música, entesa com a: 1) Mitjà d'expressió, co- municació i coneixement. 2) Procés carregat de creativitat, imaginació i improvisació. 3) Mitjà de transmissió i recepció de valors culturals.

- L'accessibilitat de la música a tothom, independentment del seu grau d'aptitud musical. Tots consideren el llenguatge musical com a proposta educativa generalitzable, i per tant integrant del currículum escolar general.

- Una pedagogia activa. La necessitat d'una pedagogia musical centrada en el nen, partint dels seus interessos i del nivell de desenvolupament psicològic.

- Metodologia global. La música entesa com a procés globalitzador.

- La música generadora de sensacions gratificants. Trets divergents

Ara bé, els principis d'aquests pedagogs reposen sobre un conjunt d'elements amb una aproximació, una filosofia tota vegada una mica diferents.

Jacques Dalcroze

- Cal remarcar el seu objectiu de desenvolupar la sensibilitat musical que porta els alumnes a buscar i trobar una percepció i una expressió musical molt profunda i molt refinada.

- És un enfocament molt complet (rítmica, solfeig i improvisació) i global perquè s'adreça a diferents dimensions de la persona intentant establir lligams entre el cos, la intel-ligència i els sentiments.

- Els partidaris de Kodàly li retreuen de fer servir poc el cant i de preocupar-se poc de l'ensenyament de la lectura i escriptura.

- Els partidaris d'Orff li recriminen de ser massa formal i de no desenvolupar suficientment la creativitat.

- La seva adaptació es fa difícil a l'aula, per la naturalesa dels exercicis, i queda reservat sovint a escoles específicament dalcrozianes.

- Les exigències, molt elevades, per aconseguir la certificació limiten enormement el nombre d'educadors musicals titulats en aquesta pedagogia.

\section{$\underline{\text { Carl Orff }}$}

- Manca de rigorositat i dificultat en el desenvolupament dels coneixements i les habilitats bàsiques musicals.

- Se li critica el material musical que proposa i fa servir. A més de les cançons, el mestre pot utilitzar qualsevol altre material que l'interessi. El resultat és sovint pobre estèticament i musicalment.

- Si la improvisació ha d'ocupar un lloc central en totes les activitats, sovint està poc explotada i es limita a fer tocar lliurement molts instruments conjuntament (preparats pentatònicament). 


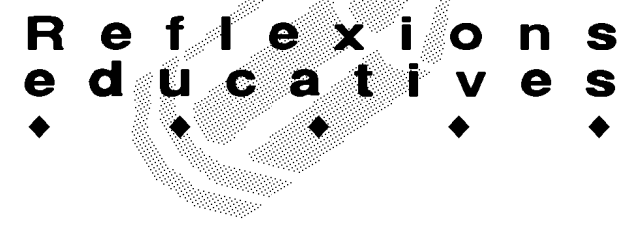

- És el que més valor dóna a l'esperit creatiu, que és l'objectiu central de tota la seva pedagogia.

Zoltan Kodàly

- És el més sistemàtic i el més detallat. És l'únic sistema d'educació musical que contempla un ensenyament sistematitzat: comença en les escoles bressol i finalitza a la universitat.

- La seva progressió és d'una minuciositat remarcable.

- Ha basat el seu ensenyament en les cançons populars del seu país, i per tant és fàcil la seva adaptació a altres llengües i a altres cultures. Ara bé, no ho és tant l'ús de l'escala pentatònica.

- Si bé el grau d'uniformitat dóna seguretat i èxit als professors hongaresos, sovint a l'estranger es considera massa rígid.

- Les exigències, molt elevades, per aconseguir la certificació limiten enormement el nombre d'educadors musicals titulats en aquesta pedagogia.

\section{Implicacions}

Cal formar el professorat per interpretar i desenvolupar el disseny curricular i no per ser un simple executor de decisions alienes, i aquesta formació no ha de ser un simple catàleg de receptes didàctiques per aplicar a l'aula d'immediata aplicabilitat, com sol passar massa sovint.

A I'hora d'escollir un enfocament o un altre s'hauria de tenir en compte altres factors, com per exemple:

- Els recursos didàctics i els mitjans d'expressió en les activitats d'aprenentatge.

- Quines habilitats es necessiten per ensenyar a partir d'un enfocament o un altre; tinguem en compte que, per exemple, Kodàly fa un gran ús de la veu i un professor amb dificultats de veu li serà difícil treballar des d'aquest model. $O$ un professor inhibit en els seus moviments tindrà problemes si opta per Dalcroze.

- El tipus de programa que pretengui seguir: estructurat $i$ ben definit o un programa obert que reposi en bona part en la creativitat del professor. És fonamental per al professor que organitzi un programa que convingui a la seva personalitat.

\section{Finalment}

Tot això que ara sembla del tot evident, en la seva època va representar un gran desenvolupament en el camp de l'educació musical. Cal remarcar que aquests pedagogs foren músics abans que pedagogs i que s'interessaran per l'educació inclinant-se per la pràctica musical com a objectiu essencial de l'educació musical enfront d'un tipus d'ensenyament excessivament teòric.

En els últims anys altres pedagogs han defensat idees semblants. Però les principals diferències entre ells es troben en la progressió del llenguatge musical i en els materials emprats, certament fruit de la influència dels corrents musicals de l'època, del recorregut personal

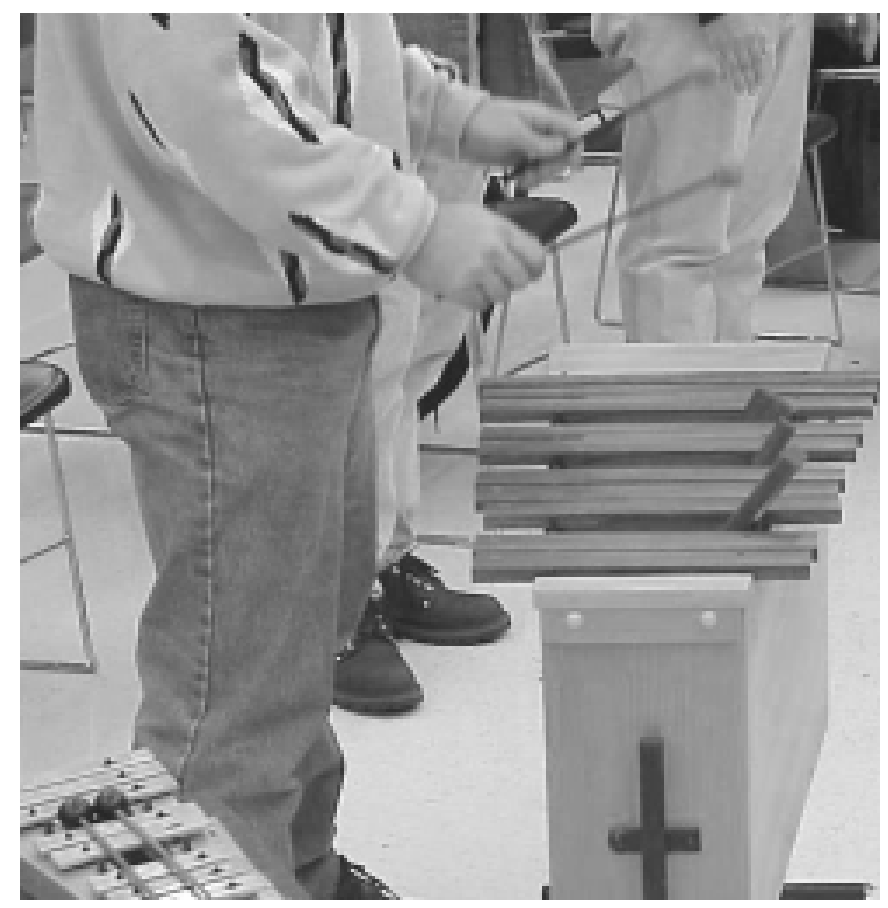

i musical de cada compositor i pedagog.

Ens sembla que el veritable objectiu de l'educació musical no està pas en el debat entre l'enfocament particular o l'enfocament eclèctic. És imprescindible i essencial que el professor justifiqui la seva visió personal de l'educació musical, de manera que pugui optar per una pràctica on coincideixin les seves conviccions personals amb els principis educatius en els quals es fonamenten els models didàctics d'aquest estudi.

\section{Bibliografia consultada}

BARNIOL, E. Didàctica de l'Expressió Musical. Edició del Servei Lingüístic de la Universitat Rovira i Virgili. Tarragona. 1997.

BARNIOL, E. Reflexiones en torno a la innovación y la investigación en la enseñanza de la música en Catalunya. I Jornadas de Investigación en Educación Musical. ISMEEspaña (Sociedad Internacional de Educación Musical). Ceuta. Octubre, 1998.

BARNIOL, E. El conocimiento del Profesorado de música de Primaria. Un ejemplo de investigación educativa. I Congrés Internacional/Investigació en Didàctica Musical. SIEM (Società Italiana per l'Educazione Musicale). Bologna. Febrer, 2000. 